\title{
Moringa oleifera-silver Nanohybrid as Green Antimicrobial Finishing for Cotton Fabrics
}

\author{
M. Hashem ${ }^{1}$, A. Elfetoh M. Abdalla ${ }^{2}$, Ehab R. Abdol \\ Raouf $^{\mathbf{3}}$, A. El-Shafei ${ }^{1}$, S. Zaghloul ${ }^{1}$ and M.K.El-Bisi ${ }^{{ }^{* *}}$ \\ ${ }^{1}$ Textile Research Division, Pre-treatment and Finishing of \\ Cellulosic Fibers Department, ${ }^{2}$ Horticultural Crops \\ Technology Department and ${ }^{3}$ Medical Division, National \\ Research Centre (Scopus affiliation ID: 60014618), 33 Bohoth \\ Street, Dokki, P.O. Box 12622, Giza 12522, Egypt.
}

\begin{abstract}
SILVER nanoparticles (AgNPs) were synthesized as colloidal synthesized as colloidal solution using Moringa oleifera extract as Moringa oleifera extract as reducing and stabilizing agents. The prepared AgNPs solution was applied onto cotton fabrics to impart them antimicrobial properties. The obtained AgNPs were characterized as per world class analysis, exemplified by ultra-visible (UV-vis) spectra and Transmission Electron Microscope (TEM) for its shape and size determination. Application of these AgNPs to cotton fabrics and evaluation of the treated fabric were done by monitoring morphological change of the fabric through Scanning Electron Microscope (SEM), also investigated towards antimicrobial and physical properties.
\end{abstract}

Keywords: Moringa oleifera, Cotton finishing, Functional finishing, Antimicrobial textiles, Green synthesis and Nanoparticles.

The nanotechnology studies were made by different techniques and can be applied in many fields such as textile, catalysis, electronic and medical ${ }^{(1-3)}$. The traditional methods are harmful, for this reason a new trend must be followed to reduce nitro compound. It was found that the novel trend for reduction is using metal nanoparticles which give less aquatic toxicity. The prepared metal nanoparticles were used as drug delivery ${ }^{(4,5)}$. For the eco-friendly nanoparticles preparation methods using plant extract or natural material ${ }^{(6)}$ are considered environmentally safe. The preparation of nanoparticles by plant extracts gives many advantages as it doesn't need elaborate processes for example, intracellular formation or multiple purification process or the protection of microbial cell cultures ${ }^{(8,7)}$. In this regard, several plants have been effectively utilized for preparation of metal nano-particles. 
Moringa plant is native to sub-Himalayan regions of, Pakistan, India, Bangladeesh, and Afghanestan as well as tropic areas. Medicine can be made from the leaves, bark, flowers, fruit, seeds, and root. Moringa oleifera is considered an important source for foods in some world parts, as it had easily and cheaply growth and its leaves have ability to retain a lot of minerals and vitamins if it had been dried ${ }^{(18)}$.

From the applications of Moringa oleifera is utilizing it directly with the human skin as it may be act as a drying agent (astringent) as well as germs-killer. It may be also utilized topically to treat pockets of infection (abscesses), dandruff, athlete's foot, snake bites, gum disease (gingivitis), wounds and warts ${ }^{(18)}$.

Materials containing silver which have antimicrobial activity can be utilized in medicine to reduce infections on the treatment of burn, inhibition of the colonization of bacteria on catheters and eliminate microorganism's presence on the fabrics ${ }^{(19)}$.

The reduction technique for synthesize silver nanoparticles is widely used in laboratory conditions. These chemical techniques were involved by hazardous materials, which may affect in the medicine and environmental applications. In addition, green synthesis approach of AgNPs will provide various advantages such as eco-friendly and clean environment as well ${ }^{(20,21)}$.

The preparation of silver nano-particles by green method such as synthesis from honey bee ${ }^{(22)}$, Citrullus Colocynthis ${ }^{(23)}$, sugar ${ }^{(23)}$. All this natural and biomaterials can be used as a reducing and stabilizing at the same time to produce silver nanoparticles (AgNPs) and at the same time they don't have harmful effect.

In this work, Moringa tea extract (ME) was utilized as reducing and stabilizer for formation of nano-silver using silver nitrate. The ultimate formed hybrid solution containing silver nanoparticles and ME was utilized to treat cotton fabric as antimicrobial finishing agent. Both AgNPs and ME have its own antimicrobial activities. Both AgNPs and ME will feeding off of the synergistic effect of the other and their combination in one hybrid solution for antimicrobial finishing of cotton fabrics, could strengthen the ultimate antimicrobial activities of the fabric. The effect of process parameters and finishing treatment condition was investigated.

\section{Materials and Methods}


Moringa oleifera leafs kindly were obtained from Egyptian Scientific Society of Moringa (ESSM), National Research Centre, Dokki, Cairo, Egypt. Sodium hydroxide, glyoxal, aluminum sulphate $\mathrm{Al}_{2}\left(\mathrm{SO}_{4}\right)_{3}$, acetic acid, hydrochloric acid, sodium carbonate, were of laboratory grade chemicals, silver nitrate was purchased from Aldrich and used without further purification . Mill desized, scoured and bleached $100 \%$ cotton fabric (poplin) was supplied by the Misr Company for Spinning and Weaving, Mehala El-Kubra, Egypt. The fabric has the following specifications: plane weave, warp $36 \mathrm{yarn} / \mathrm{cm}$, weft 30 yarn $/ \mathrm{cm}$, fabric weight, $150 \mathrm{~g} / \mathrm{m}^{2}$.

Synthesis of silver nanoparticles (AgNPs)

$5 \mathrm{~g}$ from Moringa tea leafs (powder) were inserted in conical flask and 100 $\mathrm{ml}$ of distilled water was added. The solution was boiled for $30 \mathrm{~min}$ then left to cool at ambient conditions finally filtered off.

Take $90 \mathrm{ml}$ from the extract prepared in the preceding step, in conical flask, adjust $\mathrm{pH}$ at 12 using $0.01 \mathrm{~N}$ sodium hydroxide then keep all this system under magnetic stirring, when the temperature reaches $80^{\circ} \mathrm{C}$ add $1 \mathrm{ml} 0.1 \mathrm{~N}$ silver nitrate (100ppm) and keep under magnetic stirring for $30 \mathrm{~min}^{(22)}$.

Treatment of cotton fabric with the prepared AgNPs

The cotton fabric was further purified in the laboratory by washing at $100^{\circ} \mathrm{C}$ for 60 min. using a solution containing $2 \mathrm{~g} / \mathrm{l}, \mathrm{Na}_{2} \mathrm{CO}_{3}$ and $1 \mathrm{~g} / \mathrm{l}$, Egyptol (nonionic wetting agent based on ethylene oxide condensate). The fabric was then washed several times with boiling water, then with cold water, and finally dried at ambient conditions.

Cotton fabric was treated with the prepared AgNPs as follows: the fabric was padded in solution of silver nanoparticles with concentration 50,100 and 200ppm and squeezed to a wet pick-up of ca $100 \%$, and drying at $80^{\circ} \mathrm{C}$ for 5 minutes and then was padded another time in an aqueous solution containing glyoxal $(50 \mathrm{~g} / \mathrm{l})$ and $\mathrm{Al}_{2}\left(\mathrm{SO}_{4}\right)_{3}(20 \mathrm{~g} / \mathrm{l})$, then squeezed to a wet pick-up of ca $100 \%$, followed by drying at $80^{\circ} \mathrm{C}$ for $5 \mathrm{~min}$ and thermofixation at $120^{\circ} \mathrm{C}$ for $3 \mathrm{~min}$. The samples were finally washed several times with cold water and dried at ambient condition.

\section{Characterization technique of silver nanoparticles}

Ultraviolet-visible (UV-vis) spectra

UV-vis spectra have been proved to be quite sensitive to the formation of silver colloids because AgNPs exhibit an intense absorption peak due to the surface Plasmon excitation which describes the collective excitation of 
conductive electrons in a metal.

Transmission Electron Microscopy (TEM)

Shape and size of AgNPs were practically obtained using TEM; JEOL-JEM-1200. Specimens for TEM measurements were prepared by placing a drop of colloidal solution on 400 mesh copper grid coated by an amorphous carbon film and evaporating the solvent in air at room temperature. The average diameter of the prepared AgNPs was determined from the diameter of 100 nanoparticles found in several arbitrarily chosen areas in enlarged microphotographs.

\section{Scanning Electron Microscopy Measurements}

Microscopic investigations on fabric samples were carried out using a Philips XL30 scanning electron microscope (SEM) equipped with a LaB6 electron gun and a PhilipsEDAX/DX4 energy-dispersive spectroscope (EDS). Images were taken at different magnifications (from 1509 to 30009), using scanning electrons (SEM) in accordance with the clarity of the images. Fabric samples were fixed with carbon glue and metalized by gold vapor deposition to record images.

\section{Antibacterial activity}

All antibacterial activity tests were done in triplicate to ensure reproducibility. The antibacterial activity of fabric samples was evaluated against Escherichia coli and staphylococcus aureus, (ATCC 1533) bacteria using disk diffusion method. A mixture of nutrient broth and nutrient agar in $1 \mathrm{~L}$ distilled water at $\mathrm{pH} 7.2$ as well as the empty Petri plates were autoclaved. The agar medium was then cast into the Petri plates and cooled in laminar airflow. Approximately 105 colony-forming units of $E$. coli bacteria were inoculated on plates, and then $292 \mathrm{~cm}^{2}$ of each fabric samples was planted onto the agar plates. All the plates were incubated at $37^{\circ} \mathrm{C}$ for $24 \mathrm{hr}$ and examined if a zone of inhibition was produced around samples.

Wrinkle recovery angles measurement (WRC)

Dry and wet crease recovery angles (DRA) of the treated samples were determined in warp and weft direction; according to the AATCC standard method 66-1998.

\section{Tensile strength}

Tensile strength of the fabric samples was determined by the ASTM Test Method D5035. A Q-Test 1/5 tensile tester was used. Three specimens for each treated fabric were tested in the warp direction and the average value was recorded to represent the fabric breaking load (Lb).

\section{Results and Discussion}


Examination the phytochemicals of the extract of Moringa provides the opportunity for examining an extensive variety of unique compounds fairly. Specifically, this plant category is rich with compounds that contain glucosinolates, simple sugar, isothiocyanates, and rhamnose. ${ }^{(25,26)}$. It has been reported that, Moringa extract has appropriate reducing and stabilizing characteristic during preparation of $\mathrm{AgNPs}$, where the reduction of $\mathrm{Ag}^{+}$to $\mathrm{Ag}^{\circ}$ was carried out by sugar which acts as an aldehyde to form AgNPs and stabilize the nano-structure of Ag-NPs meanwhile, glucosinolates oxidized to gluconic acid ${ }^{(22)}$.

\section{Nanoparticle composition}

The successive formation of AgNPs was indicated by the appearance of brown colour, this is because of excitation of surface Plasmon vibrations in nanosilver ${ }^{(27)}$ It was a quick interaction as demonstrated by the immediate colour change on blending the solution of silver nitrate and the aqueous extract of Moringa oleifera. This colour change demonstrates performing of redox reaction, whereby ions of $\mathrm{Ag}^{+}$are reduced to $\mathrm{Ag}^{\mathrm{o}}$ by the extract components, which are oxidized to different species ${ }^{(27)}$.

Figure 1 shows the UV-vis spectra of AgNPs, which were formed by using Moringa extract as reducing agent and with silver nitrate as silver precursor. $95 \mathrm{ml}$ from Moringa extract (MTE) were added to $\mathrm{AgNO}_{3}$ aqueous solution (100 ppm) and the solution adjusted at $\mathrm{pH} 12$ and the temperature was kept at $80^{\circ} \mathrm{C}$ for $30 \mathrm{~min}$. It is clear that from Fig. 1 that, a characteristic absorption peak at wavelength $420 \mathrm{~nm}$ which indicated the formation of silver nanoparticles by using Moringa extract as reducing and stabilizing agent. This characteristic peak is absent in Fig. 2 and Fig. 3 for Moringa extract and silver nitrated solution, respectively.

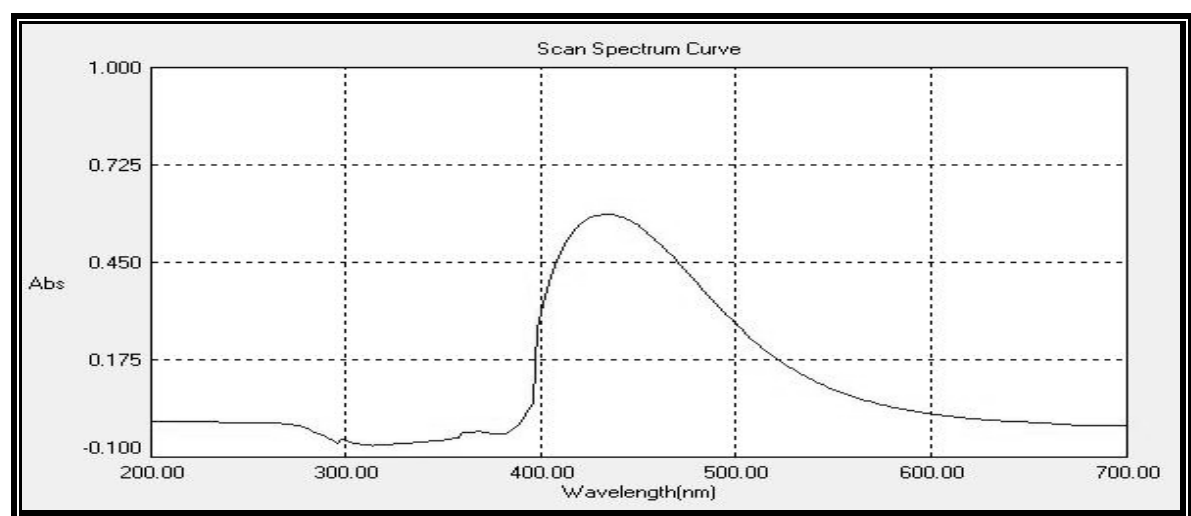

Fig. 1. UV-vis spectra of AgNPs which were formed by using moringa extract. Conditions used: Silver nitrate concentration 100 ppm, pH, 12; temperature, $80^{\circ} \mathrm{C}$ and time $30 \mathrm{~min}$. 


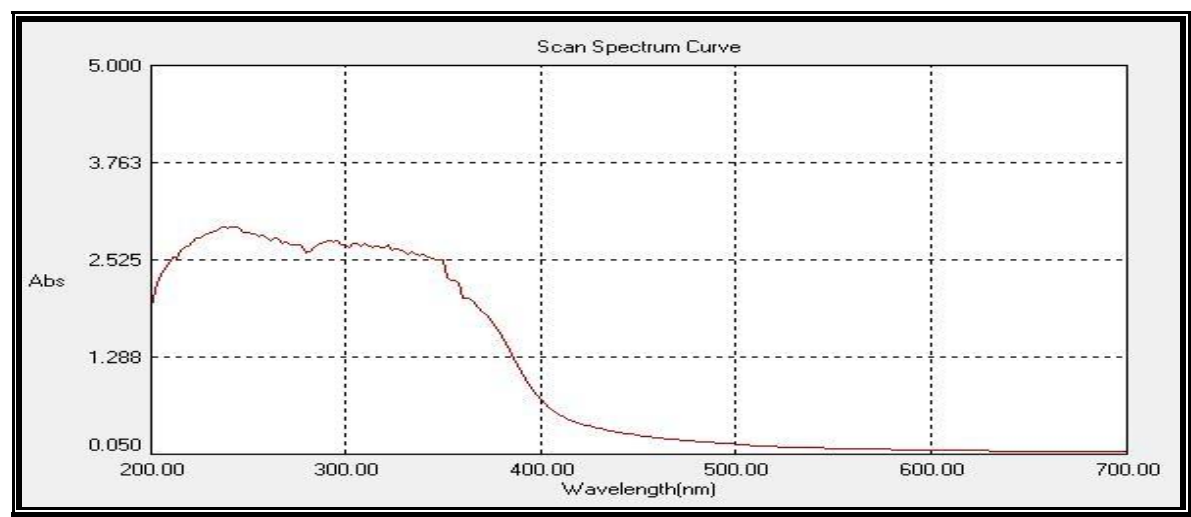

Fig. 2. UV-vis spectra of Moringa extract.

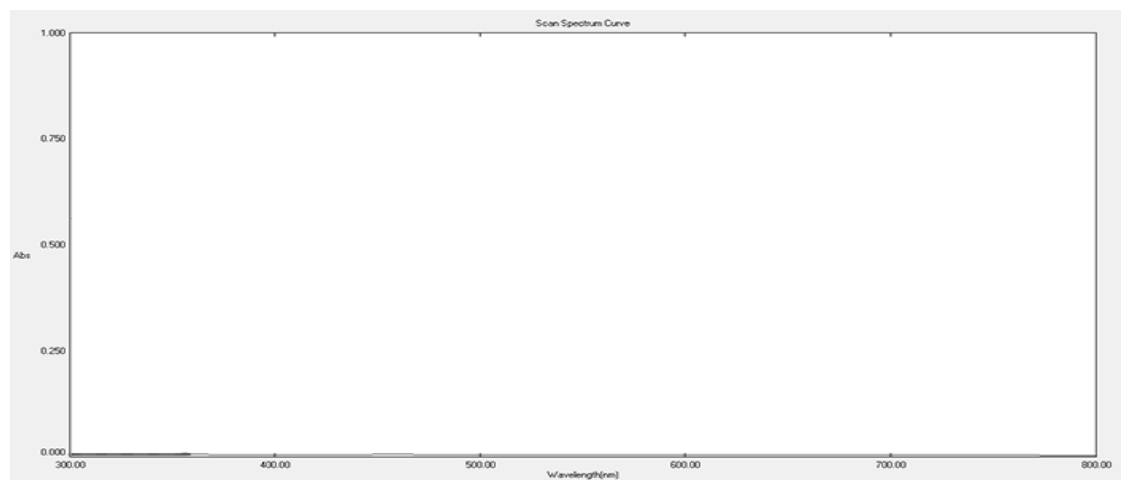

Fig. 3. UV-vis spectra of Silver nitrate solution (100 ppm).

Transmission Electron Microscope.

Figure 4 displays the transmission electron microscope picture and particle size of AgNPs formed by reaction of Moringa extract with silver nitrate according to conditions described in the experimental section. The TEM picture of AgNPs described the shape particles which were spherical and their diameter ranging from 5-9 $\mathrm{nm}$, also the figure described the particles which appear homogenous and not coagulated. These results indicated that, Moringa extract act not only as reducing to ions of silver but also as stabilizer for the preformed nano-silver, i.e. preventing silver nanoparticles from coagulation.

Egypt. J. Chem. 59, No. 4 (2016) 


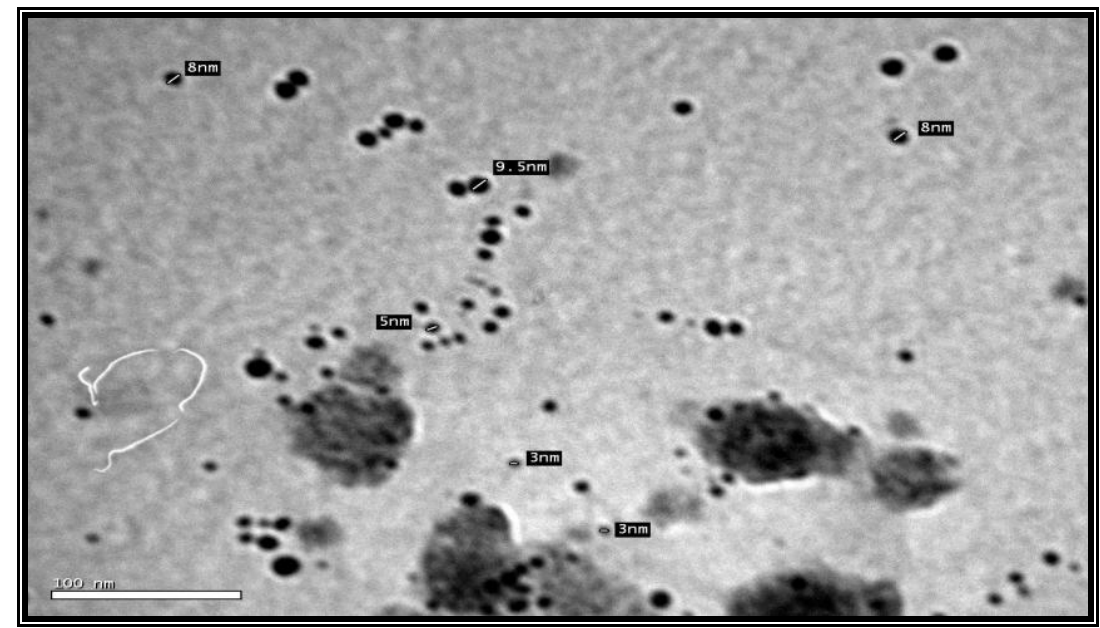

Fig. 4. TEM image of AgNPs prepared using moringa extract as reducing agent to silver nitrate.

Conditions used: silver nitrate concentration $100 \mathrm{ppm}, \mathrm{pH}, 12$; temperature, $80^{\circ} \mathrm{C}$ and time $30 \mathrm{~min}$.

Application of moringa extract-silver nanoparticles (ME-AgNPs) hybrid as antibacterial agent to cotton fabric

Although, cotton fabric is excellent in its ability in moisture absorption; the moist cotton can be attacked easily by bacteria and caused unfavorable odor $(28,29)$. The current work focuses on treating the cotton fabrics with the prepared silver nanoparticles from moringa extract tea using glyoxal as crosslinking agents. The antibacterial and physical properties of the treated fabrics were investigated.

Table 1 shows the effect of antibacterial properties of cotton fabrics treated with 50, 100 and 200 ppm ME-AgNPs hybrid. The treatment was carried out as detailed in the experimental part. The results in Table 1 show that, the treated fabrics develop inhibition zone for both E.coli and $S$. aureus whereas, the untreated fabric did not show antimicrobial activities. It is also seen from Table 1 that, cotton fabrics treated with moringa extract develop inhibition zone with diameter less than that developed with those fabrics treated with ME-AgNPs hybrid.

It is further noted from Table 1 that, the inhibition zone formed with those treated fabric increase as the concentration of AgNPs in the hybrid increased from 50 to $200 \mathrm{ppm}$. At all events, it was confirmed that the presence of nanosilver is very important to inhibit growth of bacterial on cotton surface. 
Results of Table 1 displays that, both AgNPs and ME will feeding off of the synergistic effect of the other and their combination in one hybrid solution for antimicrobial finishing of cotton fabrics strengthen the ultimate antimicrobial activities of the treated fabric.

TABLE 1. Antimicrobial activity of cotton fabric treated with different ME-AgNPs hybrid.

\begin{tabular}{||c|c|c|c|c|c||}
\hline \multirow{2}{*}{ Type of Bacteria } & \multicolumn{5}{|c||}{ Inhibition Zone diameter (mm/1cm2 sample) } \\
\cline { 2 - 6 } & \multirow{2}{*}{ Blank } & \multirow{2}{*}{$\begin{array}{c}\text { Moringa } \\
\text { extract }\end{array}$} & \multicolumn{3}{|c||}{ Conc. of AgNPs in the hybrid } \\
\cline { 4 - 6 } & & & $\mathbf{5 0}$ & $\mathbf{1 0 0}$ & $\mathbf{2 0 0}$ \\
\hline \hline Escherichia coli $\mathrm{G}^{-}$ & 0.0 & 0.5 & 4.5 & 14.5 & 19.0 \\
\hline $\begin{array}{c}\text { Straphylococcu } \\
\text { aureus } G^{+}\end{array}$ & 0.0 & 4.5 & 8.5 & 16.0 & 17.0 \\
\hline
\end{tabular}

Conditions Used: Cotton fabric treated with different concentrations of ME-AgNPs hybrid colloidal solution to $100 \%$ wet pick -up and dried at $80^{\circ} \mathrm{C}$ for $5 \mathrm{~min}$, then cured at $120^{\circ} \mathrm{C}$ for $3 \mathrm{~min}$.

Physical and mechanical properties of cotton fabric treated with ME-AgNPs hybrid

Evaluation of the changes observed in mechanical or physical properties of the pretreated fabric with ME-AgNPs were done by monitoring tensile strength and Crease recovery angle. Table 2 shows the effect of silver nano-particles concentration in the applied ME-AgNPs hybrid on tensile strength and wrinkle recovery angle of the treated fabrics.

It was found from Table 2 that,

i- The Dry wrinkle recovery angle for the treated fabrics increased with increasing ME-AgNPs concentration. The same holds true for wet recovery angle but with certainty that values of wet wrinkle recovery angle were higher than those obtained with dry recovery angle at the same concentration of MEAgNPs. Higher crease recovery angle of the treated sample compared with untreated one is attributed to the crosslinking with glyoxal. Higher wet CRA compared with dry CRA is attributed to the crosslinking reaction of glyoxal with cotton cellulose and ME-AgNPs hybrid occurs mainly in the wet state.

ii- Both tensile strength and elongation at break remain practically intact after treating the fabrics with ME-AgNPs. 
TABLE 2. Effect of ME-AgNPs concentration on physical properties of the treated cotton fabric.

\begin{tabular}{|c|c|c|c|c|}
\hline \multirow{2}{*}{ Physical properties } & \multirow{2}{*}{ Blank } & \multicolumn{3}{|c|}{$\begin{array}{c}\text { AgNPs concentration (ppm) in ME-AgNPs } \\
\text { hybrid }\end{array}$} \\
\hline & & $\mathbf{5 0}$ & 100 & 200 \\
\hline Tensile strength (kg.f) & 67 & 60 & 62 & 56 \\
\hline Elongation at break (\%) & 17 & 15 & 15 & 17 \\
\hline Dry CRA (degree) & 135 & 180 & 183 & 197 \\
\hline Wet CRA (degree) & 180 & 225 & 250 & 278 \\
\hline
\end{tabular}

Dry CRA = dry crease recovery angle, Wet CRA = wet crease recovery angle

Conditions Used: Cotton fabric treated with different concentrations of ME-AgNPs hybrid colloidal solution to $100 \%$ wet pick -up and dried at $80^{\circ} \mathrm{C}$ for $5 \mathrm{~min}$, then cured at $120^{\circ} \mathrm{C}$ for $3 \mathrm{~min}$.

\section{Scanning electron microscope (SEM)}

The deposition of ME-AgNPs onto cotton fabrics were observed by SEM micrographs. Figure 4 (a-c) displays Scanning Electron Microscope images for fabrics treated with Moringa extract unloaded and loaded with silver nanoparticles. Fig. 4 (a) displays smooth surface without any disturbed structure for untreated fabric. Otherwise, Fig. 4 (b) shows the pretreated fabric with Moringa extract tea unloaded with silver nanoparticles the surface of the fabric covered with thin film but no nanoparticles appear at all. At Fig. 4 (c) were the fabric treated with solution containing $100 \mathrm{ppm}$ silver nanoparticles which exhibit deposited on the fiber surface of cotton fabric, due to the small size of these particles it penetrated inside the cotton fabric deeply. 


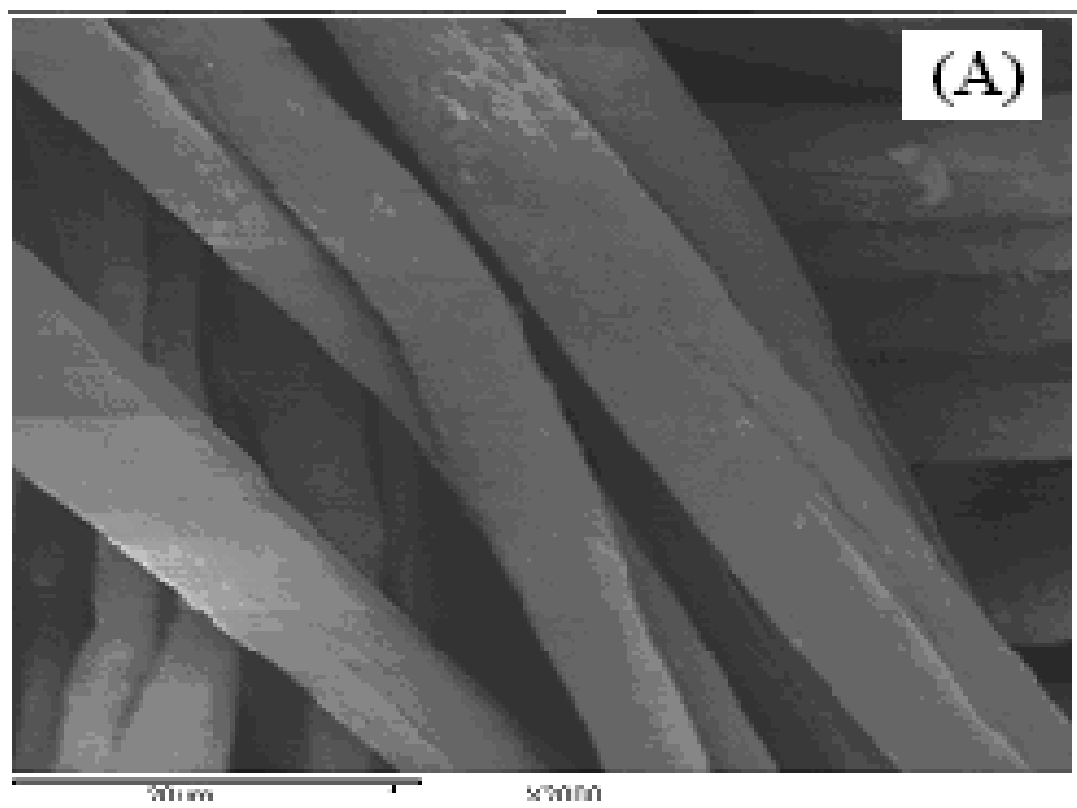

Fig. 4 (a). SEM of untreated cotton fabric.

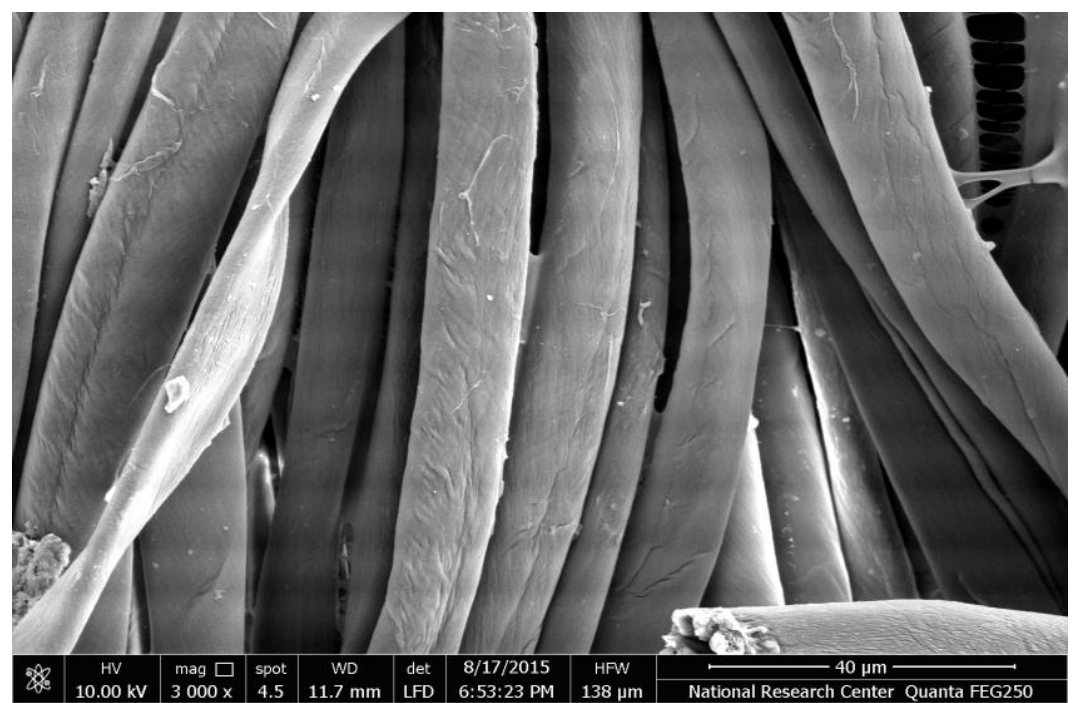

Fig. 4(b). Cotton fabric treated with moringa extract tea unloaded with silver nanoparticles.

Egypt. J. Chem. 59, No. 4 (2016) 


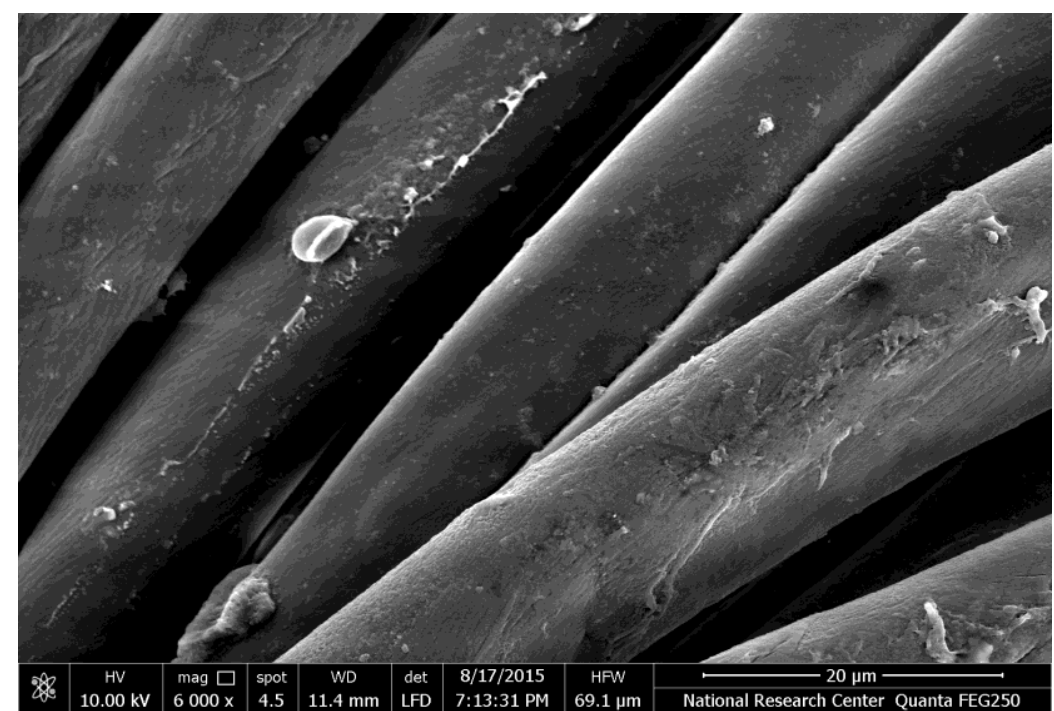

Fig. 4(c). Cotton fabric treated with moringa extract tea loaded with silver nanoparticles 100ppm.

\section{Conclusion}

Green synthesis of silver nanoparticles could be accomplished using moringa extract without any other reducing agents. Moringa tea extract (ME) acts as a reducing agent for silver ion of $\mathrm{AgNO}_{3}$ and stabilizer for the AgNPs formed thereof. Preparation process for a well-stabilized solution of silver nano-particles with a $100 \mathrm{ppm}$ concentration and with a nano-sized particle a diameter of 5-9nm could realize.

The so obtained AgNPs were successfully utilized in cotton fabrics finishing. The use of 50ppm or 100ppm and 200ppm of AgNPs in fabric treatment is quite enough to exhibit excellent antibacterial activity against E.coil and S.aureus. The SEM micrographs and analysis reveal that silver nano-particles are well dispersed as ultrafine deposits on the cotton fibers. Indeed, current treatment is considered by all means safe, cost effective, eco-friendly and innovative process for fabrication of antibacterial finishing agent which can be used as finishing of cotton textile.

Acknowledgements: This research project was supported by the Science and Technology Development Fund (STDF), Basic Research Cairo, Egypt; program code number: 5957. 


\section{References}

1. Matthew, A. Albrecht, Cameron, W. Evans and Colin, L., Green chemistry and the health implications of nanoparticles Green Chemistry, 8, 417-432, (2006).

2. (a) Cao, G. (Ed.), Nanostructures \& Nanomaterials: Synthesis, Properties \& Applications, Imperial College Press, London, 2004, p. 273;(b) Nageswara, R.N., Rohit, M., Bera, P.K., Dhodapkar, R., Bakardjieva, S., Bastl, Z., Synth React. Inorg Met. Org Chem. 40, pp.332, (2010).

3. (a) Chen, X.J., Sanchez-Gaytan, B.L., Qian, Z.X. and Park, S.J., Nanomed. Nanobiotechnol, 4 (2012) 273; $\quad$ (b) Veerapandian, M., Cytotoxicity of biosynthesized nanomaterials and functionalized nanomaterials, in: D. Yi, G. Papaefthymiou (Ed.), Nano-biomaterials Development and Applications, CRC Press, Florida, p. 417, (2013).

4. Duncan, B., Kim, C. and Rotello, V.M., J. Controlled Release 148 ,p.122, (2010).

5. Zhang, L., Gu, F.X., Chan, J.M., Wang, A.Z. and Langer, R.S., Farokhzad, O.C., Clin. Pharmacol. Ther. 83,p761, (2008).

6. (a) Sastry, M. Ahmad, A., Khan, M., Kumar, R., Niemeyer, C. and Mirkin, C., (Ed.), Microbial Nanoparticle Production,Wiley-VCH,Weinheim, Germany, 2004, p. 126. (b) Chakraborty, A., Das, D., Sinha, M., Dey, S. and Bhattacharjee, S., J. Bionanosci. 7, (2013) 5; (C) Rishalan, G., Alisa, P., Gengan, R.M., Anand, K. and Chuturgoon, A.A., J. Nanobiotechnol. 11 ,p5, (2013).

7. Bhattacharya, D. and Gupta, R., Biotechnol. Crit. Rev. 25 p.199, (2005).

8. Mohanpuria, P., Rana, N.K. and Yadav, S.K., J. Nanopart. Res. 10 ,p.507, (2008).

9. Nesamani, S., (Ed.), Medicinal Plants, Vol. I, State Institute of Languages. Thiruvananthapuram, Kerala, India, p. 425, (1999).

10. Makkar, H. S. and Becker, K., Anim. Feed Sci. Technol. 63 ,p.211, (1996).

11. Faizi, S., Siddiqui, B.S. Saleem, R., Shaheen, F. and Gilani, A.H., Planta Med. 64 pp.225, (1998).

12. Siddhuraju, P. and Becker, K., J. Agric. Food Chem. 51, p.2144, (2003).

13. Anwar, F., Latif, S., Ashraf, M. and Gilani, A.H., Phytother. Res. 21 -17, (2007).

14. Ping-Hsien Chuang, Chi-Wei Lee , Jia-Ying Chou , Murugan , M., Bor-Jinn 
Shieh and Hueih-Min Chen, Anti-fungal activity of crude extracts and essential oil of Moringa oleifera Lam, Bioresource Technology, 98, 232-236, (2007).

15. Sulaiman, M.R., Zakaria, Z.A., Bujarimin, A.S., Somchit, M.N., Israf, D.A., Moin, S., Pharm. Biol.V 46 pp.845, (2008).

16. Pari, L. and Kumar, N.A., J. Med. Food 5 pp.171, (2002).

17. Faizi, S., Siddiqui, B.S., Saleem, R., Siddiqui, S., Aftab, K., Gilani, A.H., Phytochemistry, $\mathbf{3 8}$, p.957, (1995).

18. Fuglie, L.J., The Miracle Tree: Moringa oleifera: Natural Nutrition for the Tropics. Church World Service, Dakar. 68 pp.; revised in 2001 and published as The Miracle Tree: The Multiple Attributes of Moringa, pp.172, (1999).

19. Kamyar Shameli, Mansor Bin Ahmad, Seyed Davoud Jazayeri, Parvaneh Shabanzadeh, Hossein Jahangirian and Yadollah Gharayebi, Investigation of antibacterial properties silver nanoparticles prepared via green method, Research article ,Chemistry Central Journal, 6,73pp.1-10, (2012).

20. Hebeish, A., El-Shafei, A., Sharaf, S. and Zaghloul, S., In situ formation of silver nanoparticles for multifunctional cotton containing cyclodextrin. Journal of Carbohydrate Polymers, 103, 442- 447, (2014).

21. Hebeish, A., El-Shafei, A., Sharaf, S. and Zaghloul, S., Development of improved nanosilver-based antibacterial textiles via synthesis of versatile chemically modified cotton fabrics. Journal of Carbohydrate Polymers, 113 ,455-462, (2014).

22. El-Bisi, M.K., El-Rafie H.M., El-Rafie, M. H. and Hebeish, A., Honey bee for eco-friendly green synthesis of silver nanoparticles and application to cotton textile, Egyptian Journal of Chemistry, 56 (3), 187-198 (2013).

23. El- Bisi, M.K., Allam, Abeer, O.G., El-hadi, A. and Hassanein, H.D., Citrullus colocynthis nanosilver-hybrid as antimicrobial agent. International Journal of Advanced Research, 3, 5, 1549-1559(2015).

24. Hebeish, A., El-Bisi, M.K. and El-Shafei, A., Green Synthesis of Silver Nanoparticles and Their Application to Cotton Fabrics, International Journal of Biological Macromolecules 72, 1384-1390, (2015).

25. Bennett, R.N., Mellon, F.A., Foidl, N., Pratt, J.H., DuPont, M,S., Perkins, L. and Kroon, P.A., Profiling glucosinolates and phenolics in vegetative and reproductive tissues of the multi-purpose trees Moringa oleifera L. (Horseradish tree) and Moringa stenopetala L. Journal of Agricultural and Food Chemistry, 51, 3546-3553, (2003).

26. Fahey, J.W., Zalcmann, A.T. and Talalay, P., The chemical diversity and distribution of glucosinolates and isothiocyanates among plants. Phytochemistry 56(1): 5-51. [Corrigendum: Phytochemistry, 59, pp.237 (2001). 
27. Emam, H.E. and El-Bisi, M.K., Merely Ag nanoparticles using different cellulose fibers as removable reductant, Cellulose, 21 (6), 4219-4230 (2014).

28. Su, W., Wei S.S., Hu, S.Q. and Tang, J.X., Antimicrobial finishing of cotton textile with nanosized silver colloids synthesized using polyethylene glycol, J. Text. Inst.102 (February (2)) 150-156,(2011).

29. Hebeish, A., El-Shafei, A., Sharaf, S. and Zaghloul, S., Novel precursors for green synthesis and application of silver nanoparticles in the realm of cotton finishing. Journal of Carbohydrate Polymers, 84 ,605-613 (2011).

(Received 7/6/2016; accepted 13/7/2016)

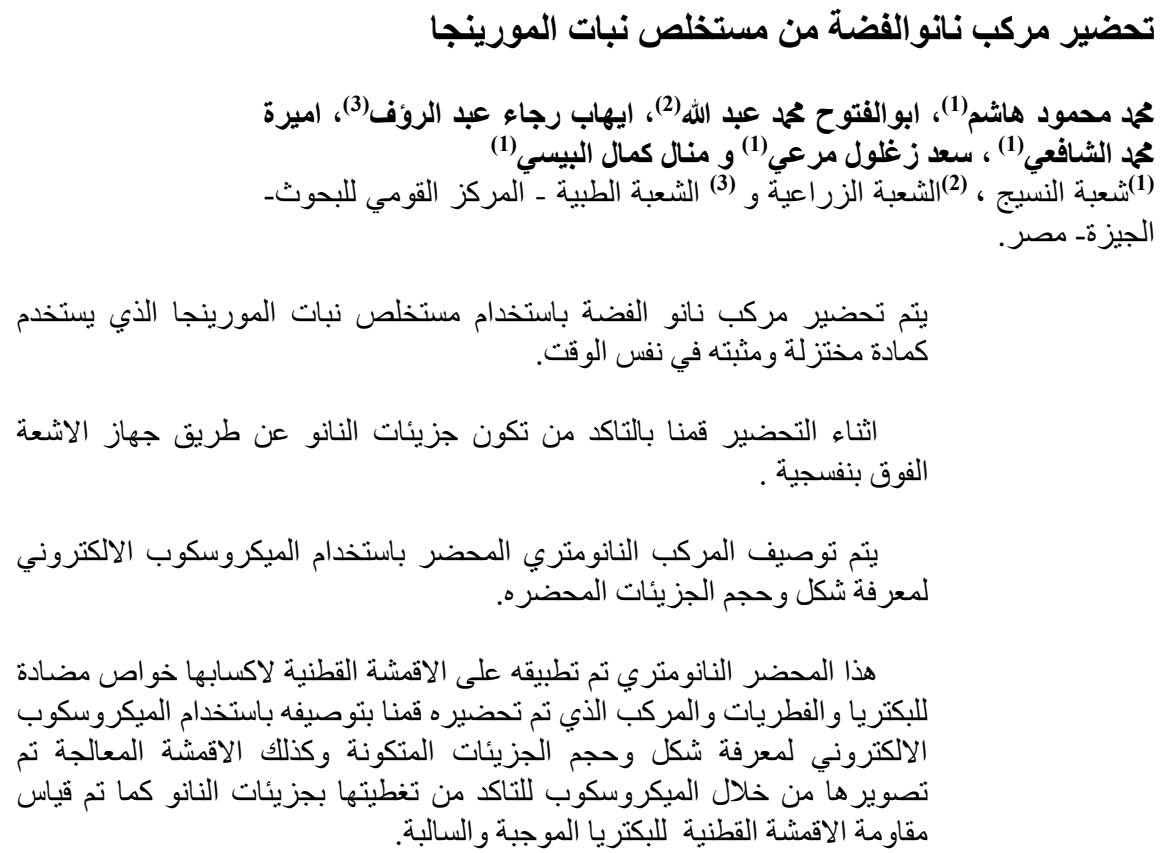


Egypt. J. Chem. 59, No.4 (2016) 